\title{
Chinese stock market sectoral indices performance in the time of novel coronavirus pandemic
}

\author{
Venus Khim-Sen Liew ( $\nabla$ ksliew@unimas.my ) \\ Universiti Malaysia Sarawak https://orcid.org/0000-0002-2305-1404 \\ Chin-Hong Puah \\ Universiti Sarawak Malaysia
}

\section{Research Article}

Keywords: Novel coronavirus, COVID-19, SARS-CoV-2, pandemic, Chinese stock market, Exponential Generalized Autoregressive Conditional Heteroscedasticity

Posted Date: May 18th, 2020

DOI: https://doi.org/10.21203/rs.3.rs-29363/v1

License: (a) This work is licensed under a Creative Commons Attribution 4.0 International License. Read Full License 


\section{Abstract}

This paper aims to quantify the effect of the deadly novel coronavirus (COVID-19) pandemic outbreak on Chinese stock market performance. Shanghai Stock Exchange Composite Index and its component sectorial indices are examined in this study. The pandemic is represented by a lockdown dummy, new COVID-19 cases and a dummy for 3 February 2020. First, descriptive analysis is performed on these indices to compare their performances before and during the lockdown period. Next, regression analysis with Exponential Generalized Autoregressive Conditional Heteroscedasticity specification is estimated to quantify the pandemic effect on the Chinese stock market. This paper finds that health care, information technology and telecommunication services sectors were relatively more pandemic-resistant, while other sectors were more severely hurt by the pandemic outbreak. The extent to which each sector was affected by pandemic and sentiments in other financial and commodity markets were reported in details in this paper. The findings of this paper are resourceful for investors to avoid huge loss amid pandemic outburst and the China Securities Regulatory Commission in handling future pandemic occurrence to cool down excessive market sentiments.

\section{Introduction}

The novel coronavirus (COVID-19) pandemic was first detected in Wuhan, Central China in December 2019 (Wuhan Municipal Health Commission, 2019)1. This human transmitted disease spread at a rapid rate to other parts of China, and then to other parts of the world23. As of 28 April 2020 , there were total of 2,883,603 confirmed cases, while the death toll had reached 198,842 cases (6.9\%) (World Health Organization, 2020). To halt the outbreak, China swiftly imposed the unprecedented lockdown in Wuhan city, the epicenter of COVID-19, and nearby cities (so-called Wuhan lockdown), starting from 23 January 2020. By mid-February, some 200 other cities around the nation had implemented similar social distancing measures, control of movement, closed management and ban on travels4. Disregarding the sudden spike on 12 February 2020 (due to diagnostic changes), it took 2 weeks after the lockdown imposition for the daily new COVID-19 confirmed cases and deaths to exhibit declining trends, see Figure 1.

While China was able to curtail the outbreak of COVID-19 by containment, its production and economy were badly affected. Businesses and factories in China were essentially scaled down if not totally shutdown in the lockdown period. Subsequently, the country's industrial profit plunged by $38.3 \%$ in the first two months of the year 2020. Meanwhile, some 5 million employees lost their jobs in the same period, with urban unemployment surged to $6.2 \%$ in February 2020, up from 5.2\% in December 2019. Moreover, barometers of economic growth such as retail sales of consumer goods and investment spending (on infrastructure, property, machinery and equipment) fell 29.5 and 24.5\% respectively (Bermingham. and Wang, 2020; Chen, 2020; National Bureau of Statistics of China, 2020; Roper, 2020). As China's economy sank to all-time low in the first two months of the year, International Monetary Fund remarked on 20 March 2020 that "China's slowdown in the first quarter of 2020 will be significant and will leave a deep mark for the year" (Berger et al., 2020). In fact, China economy shrank 6.8\% in the first quarter compared with the year before (Vaswani, 2020).

From the perspective of stock exchange, another barometer of economic growth5, Chinese stock markets had tumbled following the news of COVID-19 outbreak (Avalos and Zakraišek, 2020; Oxford Analytica, 2020). In this respect, the Shanghai and Shenzhen composite indices recorded the biggest single-day loss (2.75\% and 3.25\% respectively) in almost 9 months on 23 January 2020 (Chinanews.com, 2020a)6. On the next trading day (3 February, 2020), these two indices further suffered a gap down of $8 \%$ in the opening session. They eventually closed with a loss of $7.72 \%$ for Shanghai and $8.45 \%$ for Shenzhen composite indices, with the single day biggest loss in 12 months (Chinanews.com, 2020b). The current empirical study attempts to provide a comprehensive measure on the effect of the deadly COVID-19 outbreak on Chinese stock market performance, with reference to Shanghai Composite index and its component sectors indices.

The rest of this paper is structured as followed. The Brief Literature Overview section points out the urgency of conducting the current research. The Empirical data and descriptive analysis section describes the data sources and variables involved in this study. Besides, descriptive analysis is performed for data exploration. The Regression model section explains the ordinary least squares regression model with the EGARCH (1,1) specification employed in this study. The Regression results section presents the estimated results and interpretation of results. The last section on Conclusion and policy recommendation summarizes the key findings, suggests policy implications and concludes this paper.

\section{Brief Literature Overview}

In the recent decade, there has been a considerable surge in Chinese stock market research in conjunction to the intensifying China's influential roles on various aspects of the world including the stock exchanges. Majority of these studies focused on the efficiency (see among others, Chong et al.,, 2012; Han et al.,, 2019, Liu et al.,, 2020 and references therein) or relationship analysis between Chinese stock market with international stock markets (Zhang and Li, 2014; He et al.,, 2015; Hung, 2019), commodity markets or/and macroeconomic aspects (Ahmed and Huo, 2020; Zhuang et al.,, 2015, Jebran, 2019, Wei et al.,, 2019; Wen et al. 2019; Yousaf and Hassan, 2019; Zhao et al.., 2020 and references therein).

Remarkably, effect of financial crises on Chinese stock market was also commonly examined in the past (Jebran, 2019; Han et al.,, 2019; Hung, 2019; Lin and Tsai, 2019; Yousaf and Hassan 2019, and Wei et al.,, 2019), while studies on natural disasters were rare. Two contributions in this aspect are worthmentioning. Specifically, Li et al. (2015) examine 60 natural disaster announcements over the period 2003-2013 and find that they produced significant negative stock returns in China. Earlier on, Chong et al. (2010) report significant positive abnormal returns for pharmaceutical stocks in China, while tourism stocks were significantly affected by the severe acute respiratory syndrome (SARS) caused by coronavirus7. These two studies adopted the 
event study approach. The current study attempts to estimate the nature, magnitude and significance of effect of COVID- 19 pandemic on Chinese stock market with regression analysis that controls for the plausible financial and commodity markets spillover effects8.

\section{Empirical Data And Descriptive Analysis}

The data set spanning from 2 September 2019 to 27 March 2020 are considered in this study. To estimate the effect of COVID-19 pandemic on the Chinese stock market, Shanghai Stock Exchange Composite Index (SSE) and its component sectorial indices are employed. They are from the sectors of energy $(E N)$," materials $(M T)$,, industrials (IND),, consumer discretionary $(C D)$,, consumer staples $(C S)$,, health care $(H C)$,, financials $(F N)$," information technology (INT),, telecommunication services (TS),, and utilities (UL)9. COVID-19 pandemic is represented by a lockdown dummy (LD), the daily new confirmed cases in China (CNCC) and the first trading day after the Chinese New Year holidays (D1). $L D$ assumes a value of 1 for observations ranging from 23 January 2020 to 27 March 2020, and zero otherwise. Other financial market variables specifically the New York Stock Exchange Composite Index (NYSE), the remninbi per US dollar exchange rate (ER),, and commodity markets represented by spot gold price (GP) and crude oil WTI spot US dollar price $(O P)$ are included for control purpose. Daily financial and commodity variables are obtained from Investing.com. Daily new confirmed cases in China is obtained from Worldometer. These time series are plotted in Figure 2.

\section{Financial and commodities variables}

Figure 2 depicts that, for the first weeks upon the first official COVID-19 outbreak report to the World Health Organization (WHO), the markets in China (SSE) and US (NYSE) did not respond negatively. In the meantime, the China exchange rate and the spot gold price were continuing their value appreciation trend, while the crude oil was extending its declining trend. After the Wuhan lockdown imposition, the Chinese and US stock markets did not only behave differently in the process but they eventually ended up with significant different performances. SSE and NYSE stood at 14,102.04 and $2,976.53$ respectively on the Wuhan lockdown day. As of 27 March 2020, they remained 8,777.38 and 2,660.17. This is equivalent to a considerable loss of $60.66 \%$ for NYSE in the US and $11.89 \%$ for SSE in China within 41 trading days.

Figure 3 shows that there was an increasing trend starting from November 2019 in majority of the sectors in Shanghai Stock Exchange, and so the composite index, probably due seasonal effects 10 . This trend was extended into the middle of January 2020 or later, although WHO was officially informed of the of the new virus on 31 December 2019. For the composite index, it reached its peak at 3,115.57 (H1) on 13 January 2020 , and from there on it slipped to 2,746.61(L1) on 3 February 2020.

\section{Sectorial indices performance}

Sector-wise, both consumer discretionary and staples sectorial indices reached their peaks $(\mathrm{H} 1)$ at 2,548.69 and $11,128.32$ respectively on 13 January 2020. Besides, information technology as well as telecommunication services and health care sectorial indices further climbed to $\mathrm{H} 1$ at $4,611.15$ ( 22 January); 3,442.73 (22 January) and 6,967.30 (21 January) correspondingly, before the trend reversed. In this conjunction, it is evident from Figure 2 that, the reversal trend ended with a big dip for all sectors on 3 February 202011. In fact, on this first trading day after the extended Chinese New Year celebrations, the composite index plunged by $7.72 \%$ amid the fear of the COVID-19 pandemic rapid outbreak when millions of workforces were commuting to work. Meanwhile, all sectors were extensively down without exception, see Table 1 which highlights of percentage returns of SSE stock indices in the first three months of the year 2020.

After the deep market correction on 3 February 2020, sending the indices to their new lows (at L1) in 12 months, all these indices exhibited technical rebound with different strengths (Figure 2). In general, this round of rebound ended on $5 \mathrm{March}(\mathrm{H} 2)$, and then they started to decline again until 23 March (L2), with the exception of information technology and telecommunication sectors. As we can observe in Column 4 of Table 1 , the energy and financials sectors set for the comparatively weakest rebound12 before their indices continued with another fall to find their lower lows ( $22<\mathrm{L} 1$ ) at $1,019.20$ and 4,614.08 respectively on 23 March 202013.

As for information technology, telecommunication sectors and consumer staples, they exhibited the strongest strength in rebound to succeed their higher highs ( $\mathrm{H} 2>\mathrm{H} 1$ ) (see Figure 2) of 5,578, 3,803 and 11,229.08 on 24 February, 25 February and 5 March respectively 14 . Remarkably, they managed to pose higher lows ( $L 2>L 1)$, in the following round of price falling action, indicating a better future prospect than other sectors. The index of health care (H2 at 6 February) sector also managed to find their higher highs (compared $\mathrm{H} 1$ ) but like the majority of other sectors, it ended up with lower lows (L2 < L1). Indices which rebounded for only lower highs $(\mathrm{H} 2<\mathrm{H} 1)$ and ended up eventually with lower lows $(\mathrm{L} 2<\mathrm{L} 1)$ were materials, industrials, energy, consumer discretionary and financials.

Table 1 (Column 3) shows that the daily performances of these sectors on the 3 February, from the most wounded to the least hurt were: telecommunication services $(-9.99 \%)$, information technology $(-9.72 \%)$, industrials $(-9.03 \%)$, consumer discretionary $(-8.91 \%)$, materials $(-8.64 \%)$, energy $(-8.44 \%)$, utilities $(-7.68 \%)$, financials $(-7.28 \%)$, consumer staples $(-6.85 \%)$ and health care $(-3.22 \%)$. Indeed, this scenario was the extension of the market fears which drove all the indices far to the south on 23 January 2020, when Wuhan city was locked down 15 . The daily performances of these sectors on Wuhan lockdown day, in the same manner were: telecommunication services (-4.79\%), materials (-3.57\%), consumer staples (-3.53\%), consumer discretionary $(-3.28 \%)$, information technology $(-3.07 \%)$, industrials $(-2.96 \%)$, energy $(-2.78 \%)$, financials $(-2.73 \%)$, utilities $(-7.68 \%)$ and health care $(-2.08 \%)$ (see Column 2, Table 1$)$. 
Table 1 also reveals that the indices of consumer discretionary $(-19.45 \%)$, materials $(-16.44 \%)$ and information technology $(-15.32 \%)$ performed the worst in terms of periodic returns from 5 March to 23 March 2020. On the other hand, telecommunication services (-5.69\%) and utilities (-7.86\%) sectors experienced the smallest loss over the same period.

Table 1: Highlights of percentage returns of SSE stock indices in the early 2020

\begin{tabular}{lllll}
\hline & Daily & \multicolumn{3}{c}{ Periodic } \\
\hline Index & 23 Jan & 3 Feb & 3 Feb to 5 Mar & 5 Mar to 23 Mar \\
\hline Shanghai Stock Exchange Composite & -2.75 & -7.72 & 11.84 & -13.40 \\
Energy sector & -2.78 & -8.44 & 6.47 & -12.53 \\
\hline Materials sector & -3.57 & -8.64 & 14.14 & -16.44 \\
\hline Industrials sector & -2.96 & -9.03 & 15.45 & -13.74 \\
\hline Consumer discretionary sector & -3.28 & -8.91 & 13.44 & -19.45 \\
\hline Consumer staples sector & -3.53 & -6.95 & 15.88 & -11.36 \\
\hline Health care sector & -2.08 & -3.22 & 10.97 & -11.33 \\
\hline Financials sector & -2.73 & -7.28 & 8.13 & -14.85 \\
\hline Information Technology sector & -3.07 & -9.72 & 23.42 & -15.32 \\
\hline Telecommunication services sector & -4.79 & -9.99 & 20.92 & -5.69 \\
\hline Utilities sector & -2.04 & -7.68 & 8.68 & -7.86 \\
\hline
\end{tabular}

Note: China stock market was closed from 24 January to 2 February 2020 for Chinese New Year holidays.

Table 2 summarizes the descriptive statistics of SSE composite and sectorial indices before and during lockdown, after controlling for equal window length for the sub-samples. Indices that consistently have lower maximum, average, minimum prices during the lockdown period compared to prelockdown period are Shanghai Stock Exchange Composite Index (SSE), energy (EN) materials (MT)," industrials (IND)," consumer discretionary (CD)," financials $(F N)$, and utilities (UL).. Moreover, all their returns were turning from positive pre-lockdown to negative during lockdown, with the exception of utilities sector index which was already in the negative pre- lockdown. This means the price performance of these sectors was very much affected by the lockdown as a result of COVID-19 outbreak. In sharp contrast, health care (HC),, information technology (INT), telecommunication services (TS) sectors were able to record higher maximum, average and minimum prices during the lockdown period. In fact, health care is the only sector that was able to maintain its positive return amid the lockdown, while information technology $(-4.06 \%)$ and telecommunication services (-0.98\%) sectors suffered relatively milder losses in indices returns in the lockdown period.

Having analyze the indices price behavior and return performance before and during the lockdown to prevent COVID-19 outbreak, another key finding can be derived from Table 2. Specifically, the standard deviation of all indices were larger during lockdown in relation to pre-lock period, with the exception of industrial sector. This is probably because investors' reaction was more sensitive to COVID-19 news such that the overall Chinese stock market was relative more volatile during lockdown.

Table 2: Descriptive statistics of SSE indices before and during lockdown

\begin{tabular}{llllllllllll}
\hline Sector & $S S E$ & $E N$ & $M T$ & $I N D$ & $C D$ & $C S$ & $H C$ & $F N$ & $I N T$ & $T S$ & $U L$ \\
\hline \multicolumn{7}{c}{ Before lockdown: 19 November 2019 to 22 January 2020 (47 Observations) } \\
\hline Maximum & 3115.57 & 1311.43 & 2089.99 & 2142.36 & 2548.69 & 11128.32 & 6967.30 & 5728.18 & 4611.15 & 3442.73 & 1937.13 \\
Mean & 2991.69 & 1230.73 & 1937.31 & 2047.56 & 2374.87 & 10793.78 & 6425.86 & 5533.44 & 3955.53 & 3149.82 & 1896.75 \\
Median & 3004.94 & 1228.53 & 1920.68 & 2051.27 & 2364.70 & 10793.64 & 6384.99 & 5553.48 & 3917.71 & 3142.43 & 1895.06 \\
Minimum & 2871.98 & 1178.09 & 1775.37 & 1954.34 & 2250.94 & 10534.66 & 6187.27 & 5333.64 & 3510.85 & 2933.69 & 1843.28 \\
S.D. & 80.79 & 33.92 & 105.64 & 59.48 & 99.33 & 169.07 & 191.36 & 126.39 & 271.43 & 130.80 & 24.93 \\
\hline Skewness & -0.02 & 0.60 & 0.04 & 0.10 & 0.38 & 0.41 & 1.03 & -0.14 & 0.55 & 0.28 & -0.17 \\
\hline Kurtosis & -1.55 & -0.34 & -1.51 & -1.28 & -1.25 & -0.89 & 0.52 & -1.45 & -0.26 & -0.66 & -0.78 \\
\hline Return \% & 4.32 & 4.35 & 12.60 & 4.72 & 7.56 & -2.55 & 2.23 & 1.21 & 23.14 & 15.8 & -0.31 \\
\hline \multicolumn{7}{c}{} & Lockdown period: 23 January 2020 to 27 March 2020 (47 Observations) & & & \\
\hline Maximum & 3071.68 & 1195.24 & 2010.43 & 2102.50 & 2487.30 & 11229.08 & 7245.17 & 5419.06 & 5578.16 & 3803.48 & 1821.89 \\
Mean & 2907.10 & 1122.87 & 1880.34 & 1967.21 & 2321.78 & 10491.87 & 6876.68 & 5152.72 & 4675.81 & 3377.55 & 1760.33 \\
Median & 2943.29 & 1133.34 & 1928.03 & 2001.80 & 2371.40 & 10521.21 & 6963.39 & 5210.14 & 4556.56 & 3374.02 & 1766.31 \\
\hline Minimum & 2660.17 & 1019.2 & 1679.94 & 1813.57 & 1986.88 & 9690.30 & 6347.41 & 4614.08 & 4035.15 & 2950.24 & 1676.42 \\
S.D. & 107.86 & 48.67 & 94.45 & 74.35 & 131.05 & 328.39 & 250.99 & 226.96 & 360.69 & 198.33 & 42.59 \\
\hline Skewness & -0.65 & -0.35 & -0.66 & -0.46 & -0.95 & -0.25 & -0.51 & -0.89 & 0.69 & -0.09 & -0.38 \\
Kurtosis & -0.78 & -0.58 & -0.96 & -0.75 & -0.21 & 0.03 & -0.78 & -0.2 & -0.08 & -0.27 & -0.88 \\
\hline Return \% & -6.86 & -12.24 & -8.85 & -5.53 & -11.41 & 2.65 & 1.93 & -10.33 & -4.06 & -0.98 & -5.14 \\
\hline
\end{tabular}

Notes: Shanghai Stock Exchange Composite Index ( $S S E)$, energy $(E N)$ materials $(M T)$, industrials (IND), consumer discretionary $(C D)$, consumer staples $(C S)$, health care $(H C)$, financials $(F N)$, information technology $(I N T)$, telecommunication services $(T S)$, and utilities ( $U L)$. S.D. stands for standard deviation.

\section{Regression Model}

This study adopts regression model to quantify the effect on COVID-19 pandemic on the Chinese stock market. The following regression model is estimated: 
$I N D E X_{t}=\theta_{0}+\theta_{1} L D_{t}+\theta_{2} C N C C_{t}+\theta_{3} D 1_{t}+\theta_{4} E R+\theta_{5} N Y S E_{t}+\theta_{6} G O L D_{t}+$

$\theta_{7} O I L_{t}+\varepsilon_{t}, \quad \varepsilon_{t} \sim \mathrm{N}\left(0, \sigma_{t}^{2}\right)$,

$\underset{t}{\log \hat{\xi}}=\phi_{0}+\phi_{1}\left(\left|\hat{\varepsilon}_{t-1} / \Phi_{-1}\right|-\sqrt{2} / \pi\right)+\phi_{2}\left(\hat{\varepsilon}_{t-1} / \Phi_{-1}\right)+\phi_{3} \log \hat{\sigma}_{t-1}$

(2)

where INDEX denotes the composite or sectorial index to be tested, including Shanghai Stock Exchange Composite Index (SSE), energy (EN) materials $(M T)$," industrials $(I N D)$," consumer discretionary $(C D)$," consumer staples $(C S)$,, health care $(H C)$,, financials (FN), information technology (INT)," telecommunication services (TS), and utilities (UL) sectorial indices. In addition, ER, NYSE, GOLD and OIL represent the exchange rate of China in terms of renminbi per US dollar, New York Stock Exchange Composite Index of US, spot gold US dollar price and crude oil WTI US dollar price, accordingly. Subscript $t$ for refers to daily observation, and $\theta_{i}$ for $i=0,1, \ldots, 7$ are the parameters to be estimated. The model residuals series is denoted by $\varepsilon_{t}$ and $\sigma^{2}$ is the heteroscedastic variance of $\varepsilon_{t}$. In the meantime, $\phi_{i}$ for $i=0,1, \ldots, 3$ are the parameters to be estimated in the variance equation.

Notably, as this study estimates the effect of the COVID-19 outbreak, three proxies are included. $L D$ is the dummy variable for lockdown as a result of COVID-19 outbreak. LD assumes a value of one for dates (inclusively) ranging from 23 January 2020 to 27 March 2020, and zero otherwise. CNCC stands for daily new confirmed COVID-19 cases in China. A dummy variable (D1) is included to estimate the effect of the incident of drastic plunged in the Chinese stock market on the first trading day after the prolonged Chinese New Year holidays, amid the fears of rapid spread COVID-1916. D1 takes a value of one for the day 3 February 2020 and zero for all other dates.

It is expected that the Chinese stock market is adversely affected by the lockdown, and so the coefficient of $L D\left(\theta_{1}\right)$ should be negative, for lower index price during the lockdown period. On the other hand, CNCC signals the condition of the coronavirus outbreak with higher (lower) value means more (less) confirmed COVID-19 cases in China. A rational investor would take less cases as favorable news of improving condition and more cases as deteriorating condition. Thus, $\theta_{2}<0$ is expected. On the other hand, $\theta_{3}$ should be negative to confirm with the observations of market plunged. Importantly, the magnitude of $\theta_{1}, \theta_{2}$ and $\theta_{3}$ will reveal the extent of the COVID-19 effect on the Chinese stock market.

Equation (1) is estimated with Exponential General Autoregressive Conditional Heteroscedasticity EGARCH $(1,1)$ specification as shown in Equation (2) to model the residuals. In this respect, $\operatorname{EGARCH}(1,1)$ is commonly used to model and predict the financial time series that exhibit time-varying volatility 17,18 . Remarkably, $\phi 2$ and $\phi 3$ are of particular interest. $\phi 2$ is the asymmetry parameter. If $\phi_{2} \neq 1$, then positive and negative shocks/news, $\varepsilon_{t}$, will have asymmetric effect on the price volatility on the next day. If $\phi_{2}=0$, there is no asymmetrical behavior detected. $\phi_{3}$ is the persistence parameter. The larger (smaller) the $\phi_{3}$, the longer (shorter) it takes for the shocks/news to decay. In this respect, following Olbrys and Majewska (2017), this study measures the persistence by calculating the half-life, which is the time taken for $\varepsilon_{t}$ to be reduced to one-half of their original size. Specifically,

Half-life $=\ln (0.5) / \ln \left(\left|\phi_{3}\right|\right) \cdot(3)$

In addition, for the conditional volatility process as represented in Equation (2) to be stationary, the condition for $\left|\phi_{3}\right|<1$ must be met. Otherwise the process is explosive and the index is unpredictable.

\section{Regression Results}

The estimated regression models over the sample period spanning from 2 September 2019 to 27 March 2020 are reported in Table 319 . First and foremost, it is evident from Table 3 that the lockdown imposition to circumvent COVID-19 outbreak had exerted a significant impact on the Shanghai stock exchange, as the estimated $\theta_{1}$ coefficient is significant at $5 \%$ statistical level for the over market composite index and all its component sectors. Second, different sectors received different COVID-19 effect in terms of lockdown, depending on their nature of business. Specifically, negative effect is observed in the Shanghai Stock Exchange overall market as well as the energy, materials, industrials, consumer discretionary, consumer staples, financials and utilities sectors. In contrast, positive effect is revealed in the health care, information technology and telecommunication services sectors in specific. These sectors had benefited from their important contributions to the fight against COVID-19. Third, estimated coefficient for the lockdown to was -67.99 points for Shanghai Stock Exchange Composite Index as dependent variable. It reveals, overall, that the composite index had slumped by an average of 67.99 points significantly (as noted in the first point) in response to the lockdown, compared to the its average value before lockdown, holding other variables constant. Similarly, on average, the indices of the energy, materials, industrials, consumer discretionary, consumer staples, financials and utilities sectors were down by $129.80,52.88,60.35,64.02,693.23,272.62,148.83$ points respectively during the lockdown. Conversely, the indices for the health care, information technology and telecommunication services sectors were up by $237.46,654.92$ and 159.81 corresponding.

Fourth, the estimated coefficient $\theta_{2}$ for daily new confirmed COVID-19 cases in China (CNCC) is essentially negligible in size and it was insignificant at all for all sectors, except for financials sector $(\theta 2=-0.01, m s v<0.05)$. It reveals, in general, that the market was insignificantly affected by the new developments of COVID-19 cases.

Fifth, the estimated sign of coefficient $\theta_{2}$ is negative in all sectors. Moreover, the effect is significant for all sectors, excluding the energy and financials sectors. This indicates that the fears of COVID-19 outbreak did not only persisted but it had mounted over this long holidays with no share trading activities. Subsequently, the whole Chinese stock market reacted negatively when the market resumed trading on 3 February 2020.

Page 5/14 
Sixth, exchange rate had significant and negative effect on Shanghai Stock Exchange Composite Index (-301.66 points), materials (-612.02), industrials (-53.43), consumer discretionary (-345.26), consumer staples (-391.20), financials (-945.88), information technology (-1196.89) and telecommunication services (-1046.23). It suggests that lower (higher) indices are associated to appreciation (depreciation) of renminbi with respect to the US dollar20. In other words, depreciation of renminbi is favorable for the growth of these sectors in China. Conversely, the results indicate that appreciation of renminbi is favorable for the energy and utilities sectors.

Seventh, the US stock market as the world's leading stock market on the Chinese stock market is minute if not totally negligible as the magnitude is less than one point in all sectors. Eighth, the Chinese stock market is significant and positively related to the spot gold market. The coefficient is significant and positive for all indices with no exception. Ninth, the Chinese stock market is significant and positively affected by the crude oil market, with the exception of consumer staples (negative effect) and health care (insignificant effect).

Tenth, the estimated $\phi_{2}$ is insignificantly different from zero in all sectors, implying the absence of asymmetrical reactions on favorable or unfavorable news in the Chinese stock market. Last but not least, the estimated $\phi_{3}$ are all less than one in magnitude, implying the conditional volatility process is stationary and the index is predictable. Moreover, the half-life values calculated from estimated $\phi_{3}$ suggest fast market digestion of shocks as it took the Chinese stock market less than 3 trading days for shocks to be reduced to one-half its original size.

Table 3: Estimated regression results

\begin{tabular}{|c|c|c|c|c|c|c|c|c|c|c|c|}
\hline Sector & $S S E$ & $E N$ & $M T$ & IND & $C D$ & $C S$ & $H C$ & $F N$ & $I N T$ & $T S$ & $U L$ \\
\hline$C$ & $\begin{array}{l}3236.51 \\
0.00 *\end{array}$ & $\begin{array}{l}-242.99 \\
0.24\end{array}$ & $\begin{array}{l}4257.70 \\
0.00 *\end{array}$ & $\begin{array}{l}904.59 \\
0.00^{*}\end{array}$ & $\begin{array}{l}2339.65 \\
0.00 *\end{array}$ & $\begin{array}{l}8130.54 \\
0.00 *\end{array}$ & $\begin{array}{l}2135.08 \\
0.01 *\end{array}$ & $\begin{array}{l}9615.44 \\
0.00 *\end{array}$ & $\begin{array}{l}8027.69 \\
0.00 *\end{array}$ & $\begin{array}{l}8914.31 \\
0.00^{*}\end{array}$ & $\begin{array}{l}-98.55 \\
0.66\end{array}$ \\
\hline \multirow[t]{2}{*}{$L D$} & -67.99 & -129.80 & -52.88 & -60.35 & -64.02 & -693.23 & 237.46 & -272.62 & 654.95 & 159.81 & -148.83 \\
\hline & $0.00 *$ & $0.00^{*}$ & $0.00 *$ & $0.00 *$ & $0.00 *$ & $0.00^{*}$ & $0.00^{*}$ & $0.00 *$ & $0.00 *$ & $0.00^{*}$ & $0.00^{*}$ \\
\hline \multirow[t]{2}{*}{$C N C C$} & 0.00 & 0.00 & 0.00 & 0.00 & 0.00 & 0.01 & 0.02 & -0.01 & 0.00 & 0.00 & 0.00 \\
\hline & 0.33 & 0.34 & 0.90 & 0.99 & 0.77 & 0.49 & 0.21 & $0.02 * *$ & 0.90 & 0.72 & 0.68 \\
\hline \multirow[t]{2}{*}{ D1 } & -149.61 & -42.37 & -77.58 & -135.34 & -219.62 & -956.30 & -569.74 & -159.82 & -706.38 & -373.63 & -127.82 \\
\hline & $0.00^{*}$ & 0.89 & $0.00^{*}$ & $0.00^{*}$ & $0.00^{*}$ & $0.00^{*}$ & $0.00^{*}$ & 0.39 & $0.00^{*}$ & $0.00^{*}$ & $0.01^{*}$ \\
\hline \multirow[t]{2}{*}{$E R$} & -301.66 & 76.06 & -612.02 & -53.43 & -345.26 & -391.20 & -96.88 & -945.88 & -1198.89 & -1046.23 & 165.50 \\
\hline & $0.00 *$ & $0.00^{*}$ & $0.00^{*}$ & $0.01 *$ & $0.00 *$ & $0.00^{*}$ & 0.32 & $0.00 *$ & $0.00 *$ & $0.00 *$ & $0.00^{*}$ \\
\hline \multirow[t]{2}{*}{$N Y S E$} & -0.02 & 0.00 & -0.04 & -0.04 & 0.00 & 0.08 & 0.06 & 0.03 & -0.03 & -0.13 & -0.01 \\
\hline & 0.06 & 0.65 & $0.00 *$ & $0.00 *$ & 0.24 & $0.00^{*}$ & $0.02^{*}$ & $0.00 *$ & 0.31 & $0.00 *$ & 0.22 \\
\hline \multirow[t]{2}{*}{ GOLD } & 1.12 & 0.55 & 1.30 & 1.02 & 1.44 & 3.22 & 2.87 & 1.01 & 2.56 & 1.64 & 0.49 \\
\hline & $0.00 *$ & $0.00 *$ & $0.00 *$ & $0.00 *$ & $0.00 *$ & $0.00 *$ & $0.00 *$ & $0.00 *$ & $0.00 *$ & $0.00 *$ & $0.00 *$ \\
\hline \multirow[t]{2}{*}{ OIL } & 7.04 & 2.52 & 7.80 & 8.27 & 5.63 & -9.03 & -1.71 & 9.45 & 13.76 & 14.13 & 3.30 \\
\hline & $0.00 *$ & $0.00 *$ & $0.00 *$ & $0.00 *$ & $0.00 *$ & $0.02 *$ & 0.55 & $0.00 *$ & $0.00 *$ & $0.00 *$ & $0.00 *$ \\
\hline \multirow[t]{2}{*}{$\phi_{0}$} & 2.01 & 1.79 & 0.42 & 1.82 & 6.70 & 5.88 & 2.70 & 2.84 & 1.22 & 1.56 & 0.69 \\
\hline & 0.07 & 0.07 & 0.60 & $0.02 *$ & $0.00 *$ & $0.00 *$ & 0.12 & 0.06 & 0.36 & 0.27 & 0.42 \\
\hline \multirow[t]{2}{*}{$\phi_{1}$} & 1.38 & 1.23 & 1.45 & 1.59 & 1.61 & 1.35 & 1.78 & 1.11 & 1.67 & 1.23 & 1.41 \\
\hline & $0.00^{*}$ & $0.00^{*}$ & $0.00^{*}$ & $0.00^{*}$ & $0.00^{*}$ & $0.00^{*}$ & $0.00^{*}$ & $0.00 *$ & $0.00^{*}$ & $0.00^{*}$ & $0.00 *$ \\
\hline \multirow[t]{2}{*}{$\phi_{2}$} & 0.00 & 0.03 & -0.18 & 0.07 & 0.18 & 0.14 & 0.15 & 0.10 & 0.21 & 0.17 & 0.16 \\
\hline & 0.99 & 0.88 & 0.39 & 0.73 & 0.27 & 0.53 & 0.61 & 0.61 & 0.37 & 0.41 & 0.48 \\
\hline \multirow[t]{2}{*}{$\phi_{3}$} & 0.54 & 0.54 & 0.77 & 0.55 & -0.13 & 0.29 & 0.56 & 0.55 & 0.72 & 0.71 & 0.68 \\
\hline & $0.00 *$ & $0.00^{*}$ & $0.00 *$ & $0.00^{*}$ & 0.26 & 0.06 & $0.00^{*}$ & $0.00 *$ & $0.00 *$ & $0.00 *$ & $0.00^{*}$ \\
\hline
\end{tabular}

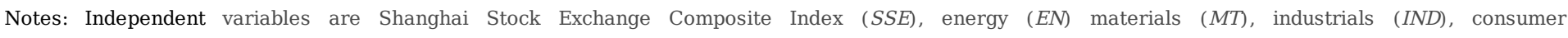
discretionary

$(C D)$,

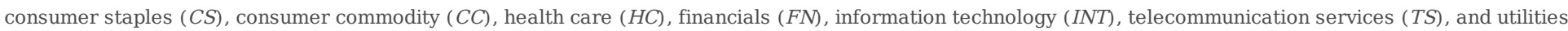

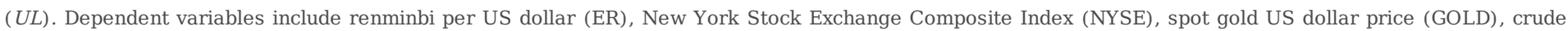

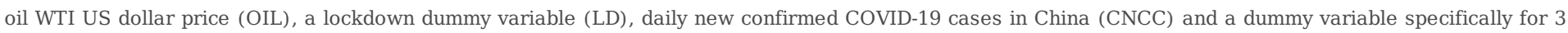
February 2020 (D1). The marginal significance value ( $m s v)$ is in italic $*$ denotes statistical significant at $5 \%$ level $(m s v<0.05$ ).

Table 3: Estimated regression results (continued)

\begin{tabular}{|c|c|c|c|c|c|c|c|c|c|c|c|}
\hline Sector & $S S E$ & $E N$ & $M T$ & $I N D$ & $C D$ & $C S$ & $H C$ & $F N$ & INT & $T S$ & $U L$ \\
\hline Half-life & 1.12 & 1.12 & 2.65 & 1.16 & 0.34 & 0.56 & 1.20 & 1.16 & 2.11 & 2.02 & 1.80 \\
\hline Adj. $R^{2}$ & 0.78 & 0.82 & 0.75 & 0.64 & 0.75 & 0.53 & 0.65 & 0.88 & 0.79 & 0.66 & 0.85 \\
\hline$A I C$ & 9.89 & 9.06 & 10.15 & 9.89 & 10.08 & 12.91 & 12.59 & 11.38 & 12.88 & 12.00 & 9.15 \\
\hline \multirow[t]{2}{*}{$Q(10)$} & 6.82 & 7.47 & 9.79 & 6.86 & 21.54 & 14.64 & 4.91 & 4.77 & 5.16 & 2.64 & 10.17 \\
\hline & 0.74 & 0.68 & 0.46 & 0.79 & $0.02 *$ & 0.15 & 0.91 & $0.05^{*}$ & 0.88 & 0.99 & 0.43 \\
\hline \multirow[t]{2}{*}{$A R C H$} & 0.01 & 0.01 & 0.06 & 0.14 & 3.56 & 0.00 & 0.62 & 0.87 & 0.14 & 0.08 & 0.01 \\
\hline & 0.91 & 0.95 & 0.81 & 0.71 & 0.06 & 0.98 & 0.35 & 0.60 & 0.71 & 0.78 & 0.93 \\
\hline \multirow[t]{2}{*}{$J B$} & 0.60 & 1.34 & 2.66 & 0.99 & 1.43 & 1.08 & 3.74 & 4.23 & 5.69 & 3.22 & 7.51 \\
\hline & 0.74 & 0.51 & 0.26 & 0.61 & 0.47 & 0.58 & 0.12 & 0.08 & 0.06 & 0.20 & $0.02 *$ \\
\hline
\end{tabular}

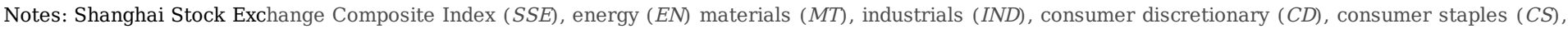

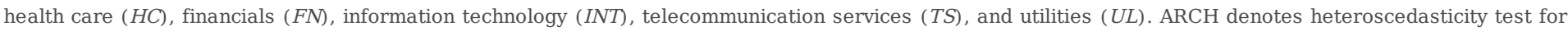

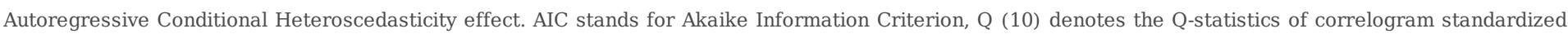

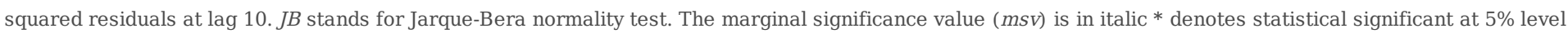
(msv<0.05). 


\section{Conclusion And Policy Implications}

The current empirical study attempts to provide a comprehensive measure on the effect of the deadly COVID-19 outbreak on Chinese stock market performance, with reference to Shanghai Composite index and its component sectors indices. The data set spanning from 2 September 2019 to 27 March 2020 are considered in this study. Shanghai Stock Exchange Composite Index and its component sectorial indices (energy, materials, industrials, consumer discretionary, consumer staples, health care, financials, information technology, telecommunication services, and utilities are examined. COVID-19 is represented by a lockdown dummy (LD), the daily new confirmed cases in China (CNCC) and a proxy for the first trading day after the Chinese New Year holidays. Financial market variables specifically the New York Stock Exchange Composite Index (NYSE) and exchange rate (ER), and commodity markets represented by spot gold price $(G P)$ and crude oil WTI spot US dollar price $(O P)$ are included for control purpose.

Few key findings could be drawn from the numerical analysis over the Chinese stock markets data. First, when the market resume trading after a prolonged Chinese New Year celebrations, the composite index unreservedly plunged by $7.72 \%$ amid the extended fear of the COVID-19 rapid outbreak. With no exception, all sectors were extensively down and the daily performances of these sectors on the 3 February 2020 , from the most wounded to the least were: telecommunication services $(-9.99 \%)$, information technology $(-9.72 \%)$, industrials $(-9.03 \%)$, consumer discretionary $(-8.91 \%)$, materials $(-$ $8.64 \%)$, energy $(-8.44 \%)$, utilities $(-7.68 \%)$, financials $(-7.28 \%)$, consumer staples $(-6.85 \%)$ and health care $(-3.22 \%)$. In fact, on $23 \mathrm{January} 2020$, when Wuhan city was locked down, there was already one round of market considerable drop. The daily performances of these sectors in the same manner were: telecommunication services $(-4.79 \%)$, materials $(-3.57 \%)$, consumer staples $(-3.53 \%)$, consumer discretionary $(-3.28 \%)$, information technology $(-$ $3.07 \%)$, industrials $(-2.96 \%)$, energy $(-2.78 \%)$, financials $(-2.73 \%)$, utilities $(-7.68 \%)$ and health care $(-2.08 \%)$. Second, after the deep market correction on 3 February 2020, sending the indices to their new lows in 12 months, all these indices exhibited technical rebound with different strengths. In general, the energy and financials sectors set for the comparatively weakest rebound, while information technology, telecommunication sectors and consumer staples exhibited the strongest strength in rebound (Table 1). These findings suggest investors who hold shares should close their trades to avoid huge loss, as soon as quality information on negative shocks are received. Besides, short-term investors could buy low whenever there is a substantially dip in the market and close the trade within 5 to 10 trading days upon technical rebound for sizable profits. On the other perspective, the China Securities Regulatory Commission should immediately prohibit short-selling for considerate period in handling future events of pandemic outbreak and other crisis. This could avoid market over-reaction and to reduce market volatility.

Third, sub-sample analysis for the composite and sectorial indices before and during lockdown, with equal window length reveals that all the indices returns of materials, industrials, consumer discretionary and financials sectors dropped from positive to negative after the lockdown as a result of COVID-19 outbreak. Contradictory, health care is the only sector that was able to maintain its positive return amid the lockdown, while information technology and telecommunication services sectors suffered mild losses in indices returns in the lockdown period.

Fourth, the standard deviation of all indices were larger during lockdown in relation to pre- lockdown period, with the exception of industrial sector, implying the Chinese stock market as a whole turned relatively more volatile during lockdown (Table 2). In this respect, risk adverse investors are advised to stay away from the market amid pandemic outbreak or crisis in the future.

First, different sectors received significant but different COVID-19 effect in terms of lockdown, depending on their nature of business. Specifically, overall, Shanghai Stock Exchange Composite Index slumped by an average of 67.99 points significantly in response to the lockdown. In the meantime, the indices of the energy, materials, industrials, consumer discretionary, consumer staples, financials and utilities sectors were down by $129.80,52.88$, $60.35,64.02,693.23,272.62,148.83$ points respectively during the lockdown. Conversely, the indices for the health care, information technology and telecommunication services sectors were up by $237.46,654.92$ and 159.81 corresponding. This reveals that health care, information technology telecommunication services sectors are potential avenues for profit-seeking in the time of pandemic outbreak.

Second, the fears of COVID-19 outbreak had mounted over the prolonged Chinese New Year holidays with no share trading activities. Subsequently, the all indices in the Chinese stock market was negative and significant when the market resumed trading on 3 February 2020, confirming the significance of the findings from descriptive analysis. On the other hand, the estimated results suggest that the Chinese stock market was insignificantly affected by the new developments of COVID-19 cases, probably the effect was overshadowed by the other two COVID-19 proxies.

Third, it is found that depreciation of renminbi is favorable for the growth of materials, industrials, consumer discretionary, consumer staples, financials, information technology and telecommunication services sectors in China. Conversely, appreciation of renminbi is favorable for the energy and utilities sector, probably due to the oil importing nature of China. As such, the Chinese government should maintain a fair renminbi in order to promote its economic growth by expanding its exports on consumer and industrial products as well as information technology and telecommunication services.

Fourth, the Chinese stock market is significant and positively related to the spot gold market and crude oil market in general. Thus, these two commodity markets are not suitable avenue for investment diversification. However, investors could detect the sentiments in these commodity markets for plausible trading signals for the Chinese stock market.

Fifth, this study finds no asymmetrical reactions on favorable and unfavorable shocks in the Chinese stock market. Nevertheless, these shocks were digested quickly as it took the Chinese stock market less than 3 trading days for shocks to be reduced to one-half its original size. This suggests that the 
COVID-19 effect on the Chinese stock market in general and the various sectors in the country specifically is not persistent and hence these sectors will recover very soon upon removal of lockdown and when the pandemic is over.

\section{Foot Notes}

1 On 31 December 2019, World Health Organization (WHO) China Country Office was officially informed of the new virus with a total of 27 cases detected.

2 On 30 January 2020, WHO declared the outbreak an International Emergency. On 11 February 2020, WHO assigned it the name of SARS-CoV2 for Severe Acute Respiratory Syndrome Coronavirus 2, and COVID-19 for Coronavirus Disease discovered in 2019.

3 The total number of confirmed cases in China were 27; 11,791; 79,824 and 81,584 for 31 December 2019, 31 January

2020, 29 February 2020 and 31 March 2020 respectively. On 11 January 2020, China reported the first and only death case (in China, and also the world) due to COVID-19 for that day. By the end of January, February and March 2020, total confirmed deaths were 259; 2,890 and 3,312 correspondingly.

4 The lockdown was finally lifted on 25 March 2020, after 8 weeks of imposition for areas except Wuhan, while lockdown in Wuhan was lifted in 8 April (The State Council Republic of China, 2020a; Hubei Novel Coronavirus Prevention and Control Center, 2020; Wikipedia, 2020).

5 For the role of exchange market in fostering economic growth, see for instance World Federation of Exchanges (2017).

6 The last trading day before Chinese New Year holidays (24 to 31 January 2020). The holidays were prolonged to 2 February 2020 to contain COVID-19 outbreak (Moon et al., 2020; The State Council Republic of China, 2020b). Hence, the stock markets in China was closed from 24 January to 2 February 2020.

7 SARS first emerged in the human population near Guangdong, China in November 2002. SARS is alternatively known as SARS-CoV.

8 See Abdelhedi and Boujelbène-Abbes (2020).

9 See, China Securities Index Co., Ltd. (n.d.) for a list of SSE component sectors.

10 See, among others, Yuan and Gupta (2014), Casalin (2018), Chia and Teng (2018) and Wagner et al. (2019) for significant positive holidays, new year and Chinese new year effects in China market. Meanwhile, better trade outlook as the US-China tariffs tension diminished may had also contributed (Li, 2020).

12 These indices registered a rise of $6.47 \%$ and $8.13 \%$ corresponding, from 3 February until the end of this rebound on 5 March (H2), see Column 4 , Table 1.

13 Equivalent to a drop of $-12.53 \%$ (energy) and $-14.85 \%$ (financials) from 5 March to 23 March. Utilities sector ranked the third in terms of weakness in strength of renouncing (8.68\%) but it only dropped to a low (L2) of 1,678 on 19 March, which was 2 points higher than its previous low (L1) of 1,676.

14 A rise of 38.4\% (information technology) and 28.9\% (telecommunication), counting from L1 on 3 February 2020.

15 It was coincidently the last trading day before the Chinese New Year holidays. See Footnote 6.

16 Another purpose for the inclusion of $D 1$ is to normalized the model's residuals.

17 See Nelson (1991) for more information on EGARCH model. See Lin (2018), for instance, for the application of GARCH family models in SSE Composite Index. Lin (2018) reports that EGARCH $(1,1)$ model outperforms the other GARCH models in both in-sample fitting and out-of-sample forecast performances for this index.

18 In fact, the residuals of Equation (1) estimated by the ordinary least squares (OLS) regression principle exhibit ARCH effect. Moreover, they do not pass the serial correlation test (results are omitted here to conserve space).

19 Except for the dummy variables, all variables included in Equation (1) are stationary in their level by the augmented Dickey-Fuller unit root test. These variables are found to be cointegrated various indices based on the Phillips-Ouliaris residual-based tests for cointegration. Both sets of results are omitted here to conserve space.

20 For instance, a one renminbi appreciation in the Chinese currency with respect to US dollar can be associated to and a drop of 301.66 point in the composite index.

\section{Declarations}

Availability of data and materials 
Data set is available upon results

Funding

Self-funded

Authors' contributions

Venus Khim-Sen Liew is responsible for the research idea conceptualization, data curation, empirical analysis, as well as writing, reviewing and editing the original draft. Chin-Hong

Puah collects resources, reviews the literature and the drafted version. Both authors

reviewed and approved the final draft.

Acknowledgements

This research is completed under the university's work-from-home policy.

Competing interests: The authors declare no competing interests.

\section{References}

1. Abdelhedi, M. \& Boujelbène-Abbes, M. (2020). Transmission of shocks between Chinese financial market and oil market. International Journal of Emerging Markets, 15 (2), 262 - 286. DOI 10.1108/IJOEM-07-2017-0244

2. Ahmed, A.D. \& Huo, R. (2020). Volatility transmissions across international oil market, commodity futures and stock markets: Empirical evidence from China. Energy Economics, In press. https://doi.org/10.1016/j.eneco.2020.104741

3. Avalos, \& Zakraišek, E. (2020). Covid-19 and SARS: what do stock markets tell us? BIS Quarterly Review, 01 March 2020. https://www.bis.org/publ/qtrpdf/r_qt2003w.htm

5. Bangkok Post (2020). Wuhan reopens after two-month 28 Mar 2020. https://www.bangkokpost.com/world/1888260/wuhan-reopens-after-twomonth-lockdown. Accessed 2 April 2020.

7. Bermingham, F. \& Wang, O. (2020). Coronavirus: China's economy suffers dramatic collapse in January, February in warning to rest of world. South China Morning Post, 16 March 2020. https://www.scmp.com/economy/china-economy/article/3075314/coronavirus-caused-dramatic- collapsechinas-economy-warning. Accessed 27 March 2020.

8. Business World (2020). The barometer of economic March 26, 2018. https://www.bworldonline.com/the-barometer-of-economic-health/. Accessed 27 March 2020.

9. Casalin, F. (2018). Determinants of holiday effects in mainland Chinese and Hong-Kong markets. China Economic Review, $49,45-67$. https://doi.org/10.1016/j.chieco.2017.12.011

11. Chen, A., Yang, J.T, Yang W.Z., Wang, C. \& Bärnighausen, T. (2020). COVID-19 control in China during mass population movements at New Year. The Lancet, 395, 754 - 766. https://doi.org/10.1016/S0140-6736(20)30421-9

12. Cheng, E. (2020). Roughly 5 million people in China lost their jobs in the first 2 months of 2020. CNBC, Mar 16 https://www.cnbc.com/2020/03/16/china-economy-millions-lose-their-jobs-as-unemployment-spikes.html. Accessed 26 March 2020.

13. China Securities Index Co., Ltd. (n.d.). Methodology of SSE sector indices. http://www.csindex.com.cn/uploads/indices/detail/files/en/36_000039_Index_Methodology_en.p df. Accessed 25 March 2020.

14. ChinaNews.com (2020a). Year of the pig official closing day: A-shares plunged, SSE Composite Index closed below 3000 (in Chinese). 23 January 2020. http://www.chinanews.com/cj/2020/01- 23/9068183.shtml. Accessed 25 March 2020.

15. ChinaNews.com (2020b). Year of the rat market opens with 3177 A-shares hit their daily downside limits, 20 billion yuan foreign funds were buying low. 3 February 2020. http://finance.chinanews.com/cj/2020/02-03/9077187.shtml. Accessed 27 March 2020.

16. Chong, T.T.L., Lam, T.H. \& Yan, I. K.M. (2012). Is the Chinese stock market really inefficient? China Economic Review, $23(1), 122$ - 137. https://doi.org/10.1016/j.chieco.2011.08.003

17. Chong, T.T.L., Lu, S. \& Wong, W.K. (2010). Portfolio Management during Epidemics: The Case of SARS in China. SSRN Paper. http://dx.doi.org/10.2139/ssrn.1673671

18. Dickey, D.A. \& Fuller, W.N. (1979). Distribution of the estimators for autoregressive time series with a unit root. Journal of the American Statistical Association, 74 (366), $427-431$.

19. Han, Y., Wang, Y.M. \& Xu, Y.Y. (2019). Efficiency and Multifractality Analysis of the Chinese Stock Market: Evidence from Stock Indices before and after the 2015 Stock Market. Sustainability, 11, 1 - 15. doi:10.3390/su11061699

Page 9/14 
20. He, H.B., Chen, S., Yao, S.J., \& Qu, J.H. (2015). Stock market interdependence between China and the world: A multi-factor R-squared approach. Finance Research Letters, 13, 125 - 129. https://doi.org/10.1016/j.frl.2015.02.005

21. Hubei Novel Coronavirus Prevention and Control Center (2020). Hubei Novel Coronavirus Prevention and Control Center Notice (in Chinese). 24 March 2020. http://www.hubei.gov.cn/zhuanti/2020/gzxxgzbd/zxtb/202003/t20200324_2189256.shtml. Accessed 28 March 2020.

22. Hung, N.T. (2019). Return and volatility spillover across equity markets between China and Southeast Asian countries. Journal of Economics, Finance and Administrative Science, 24 (47), 66 - 81.

23. Berger, H., Kang, K. \& Rhee, C. (2020). Blunting the Impact and Hard Choices: Early Lessons from China IMFBlog, March 20, https://blogs.imf.org/2020/03/20/blunting-the-impact-and- hard-choices-early-lessons-from-china/

24. Jebran, K. (2019). Volatility spillover between stock and foreign exchange market of China: evidence from subprime Asian financial crisis. Journal of Asia Business Studies, 12 (2), 220-232. https://doi.org/10.1108/JABS-01-2016-0003

25. Phillips, P. \& Ouliaris, S. (1990). Asymptotic properties of residual based tests for cointegration. Econometrica, 58 (1), 165 - 193.

26. Li, G. (2020). China's CSI 300 index rises to eight months high, as mainland investors snap up stocks on improved trade outlook. South China Morning Post, 17 December 2019. https://www.scmp.com/business/article/3078219/hong-kong-china-stock-traders-brace-more- coronavirusvolatility. Accessed 25 Mar 2020

27. Li, , Tang, H. L. \& Liao, J.C. (2001). The intraday effect of nature disaster and production safety accident announcement based on high-frequency data from China's stock markets. China Finance Review International, 5 (3), 277 - 302.

28. Lima, J.M. (2020). Live / Covid-19 Coronavirus news: How the telecoms world is dealing with the Capacity $\quad 30$ March 2020. https://www.capacitymedia.com/articles/3825122/live-covid-19-coronavirus-news-how-the-telecoms-world-is-dealing-withthe-pandemic. Accessed 10 April 2020.

29. Lin, W.Y. \& Tsai, I.C. (2019). Black swan events in China's stock markets: Intraday price behaviors on days of volatility. International Review of Economics and Finance, 59, 395 - 411. https://doi.org/10.1016/j.iref.2018.10.005

30. Lin, Z. (2018). Modelling and forecasting the stock market volatility of SSE Composite Index using GARCH models. Future Generation Computer Systems, 79 (3), 960 - 972. https://doi.org/10.1016/j.future.2017.08.033

31. Liu, B., Xia, X.Y. \& Xiao, W. (2020). Public information content and market information efficiency: A comparison between China and the U.S.. China Economic Review, 60, In Press. https://doi.org/10.1016/j.chieco.2020.101405

32. Moon, L., Bray, C. \& Yiu, E. (2020). China halts stock trading in extended Lunar New Year holiday as deadly coronavirus outbreak from Wuhan takes its toll. South China morning Post, 27 January 2020. https://www.scmp.com/business/markets/article/3047765/hong-kong-markets-open-normalamid-wuhan-coronavirus-fears-bourse. Accessed 2 April 2020.

33. National Bureau of Statistics of China (2020). Industrial Profits decreased 3 percent in the First Two Months of 2020.30 March 2020. http://www.stats.gov.cn/english/PressRelease/202003/t20200330_1735482.html. Accessed 2 April 2020.

34. Nelson, B. (1991). Conditional heteroscedasticity in asset returns: a new approach. Econometrica, 59, 347-370.

35. New Straits Times (2020). Covid-19 pandemic to hit growth in Asia, China - World 3 April 2020. https://www.nst.com.my/business/2020/03/579772/covid-19-pandemic-hit-growth-asia-china-world-bank. Accessed 8 April 2020.

36. Olbrys, J. \& Majewska, E. (2017). Asymmetry effects in volatility on the major European stock markets: the EGARCH based approach. Quantitative Finance and Economics, 1 (4), 411 - 427. https://www.aimspress.com/fileOther/PDF/QFE/QFE-01-00411.pdf

37. Oxford Analytica (2020). Financial market buoyancy is fragile amid rising risks. Expert Briefings, 28 January https://www.emerald.com/insight/content/doi/10.1108/OXAN- DB250292/full/html. Accessed 24 March 2020.

38. Price, D., Choy, G. \& Magramo, K. (2020). Asia-Pacific markets mixed as coronavirus infections reach 1 million and US weekly jobless claims hit 6.6 million. South China Morning Post, 3 April https://www.scmp.com/business/money/article/3078224/asia-pacific-markets-mixed-coronavirusinfections-reach-1-million. Accessed 23 March 2020.

39. Roper, (2020). Chinese Economy Hit Hard by Coronavirus Outbreak. Statista, 17 March 2020. https://www.statista.com/chart/21135/production-andsales-losses-in-china/. Accessed 24 March 2020.

40. Trace Media Ltd. (2020). COVID-19: Consequences and opportunities for the ICT sector. Telecom Review, 05 March 2020. https://telecomreview.com/index.php/articles/reports-and- coverage/3703-covid-19-consequences-and-opportunities-for-the-ict-sector. Accessed 17 April 2020.

41. Teng, C. C. \& Yang, J. (2018). Chinese lunar new year effect, investor sentiment, and market deregulation. Finance Research Letters, 27,175 - 184. https://doi.org/10.1016/j.frl.2018.03.003

42. The Star (2020). China's tech and internet firms see growth amid Covid-19 fight. 21 February 2020. https://www.thestar.com.my/news/regional/2020/02/21/china039s-tech-and-internet-firms-see-growth-amid-covid-19-fight. Accessed 17 April 2020.

43. The State Council Republic of China (2020a). Timeline of China's fight against the novel Top News, 19 March 2020. http://english.www.gov.cn/news/topnews/202003/19/content_WS5e736ce7c6d0c201c2cbef8f.ht ml. Accessed 2 April 2020.

44. The State Council Republic of China (2020b). China extends Spring Festival holiday to contain coronavirus Latest Release, 27 January 2020.http://english.www.gov.cn/policies/latestreleases/202001/27/content_WS5e2e34e4c6d019625c6 html. Accessed 28 March 2020. 
45. The World Bank (2020). East Asia and Pacific: Countries Must Act Now to Mitigate Economic Shock of COVID-19. Press Release, March 30, 2020. https://www.worldbank.org/en/news/press- release/2020/03/30/east-asia-and-pacific-countries-must-act-now-to-mitigate-economic-shock- ofcovid-19. Accessed 16 April 2020.

46. Vaswani, K. (2020). China GDP: Bleak outlook for economic recovery post-virus. BBC News, 17 April 2020. https://www.bbc.com/news/business52305259

47. Wagner, N. F., Weber, K. \& Kinateder, H. (2019). Revisiting calendar anomalies in BRICS countries. Bulletin of Monetary Economics and Banking, 22 (2), 213 - 236. doi: https://doi.org/10.21098/bemp.v22i2.1092

48. Wei, , Qin, S. K., Li, X.F., Zhu, S. \& Wei, G.W. (2019). Oil price fluctuation, stock market and macroeconomic fundamentals: Evidence from China before and after the financial crisis. Finance Research Letters, 30, 23 - 29. https://doi.org/10.1016/j.frl.2019.03.028

49. Wen, S.B., An, H.Z., Huang, S.P. \& Liu, X.Y. (2019). Dynamic impact of China's stock market on the international commodity market. Resources Policy, 61, 564 - 571. https://doi.org/10.1016/j.resourpol.2018.06.009

50. Who Health Organization (2020). Novel Coronavirus - China. Disease outbreak news, 12 January 2020. https://www.who.int/csr/don/12-january2020-novel-coronavirus-china/en/. Accessed 28 March 2020.

51. Wikipedia (2020). 2020 Hubei lockdowns. https://en.wikipedia.org/wiki/2020_Hubei_lockdowns

52. World Economic Forum (2020). The IMF explains the economic lessons from China's fight against The IMF Blog, 21 Mar 2020. https://www.weforum.org/agenda/2020/03/imf- economic-lessons-from-china-fight-against-coronavirus/. Accessed 15 April 2020.

53. World Federation of Exchanges (2017). The role of stock exchanges in fostering economic growth and sustainable WFE-UNCTAD Report. https://unctad.org/en/PublicationsLibrary/WFE_UNCTAD_2017_en.pdf. Accessed 27 March 2020.

54. Wuhan Municipal Health Commission (2019). Wuhan Municipal Health Commission report on the pneumonia epidemic situation (in Chinese). 31 December 2019. http://wjw.wuhan.gov.cn/front/web/showDetail/2019123108989._Accessed 24 March 2020.

55. Yousaf, I. \& Hassan, A. (2019). Linkages between crude oil and emerging Asian stock markets: New evidence from the Chinese stock market crash. Finance Research Letters, 31 (4), 207 - https://doi.org/10.1016/j.frl.2019.08.023

56. Yuan, T. \& Gupta, R. (2014). Chinese lunar new year effect in Asian stock markets, 1999-2012. The Quarterly Review of Economics and Finance, 54 (4), 529 - 537. https://doi.org/10.1016/j.qref.2014.06.001

57. Zhang, \& Li, X. M. (2014). Has there been any change in the comovement between the Chinese and US stock markets? International Review of Economics and Finance, 29, 525 - 536. https://doi.org/10.1016/j.iref.2013.08.001

58. Zhao, Z., Wen, H.W. \& Li, K. (2020). Identifying bubbles and the contagion effect between oil and stock markets: New evidence from China. Economic Modelling, In press. https://doi.org/10.1016/j.econmod.2020.02.018

59. Zhuang, X.Y., Wei, Y. \& Ma, F. (2015). Multifractality, efficiency analysis of Chinese stock market and its cross-correlation with WTI crude oil price. Physica A: Statistical Mechanics and its Applications, 430, 101 - 113. https://doi.org/10.1016/j.physa.2015.02.085

\section{Figures}


Total new confirmed cases

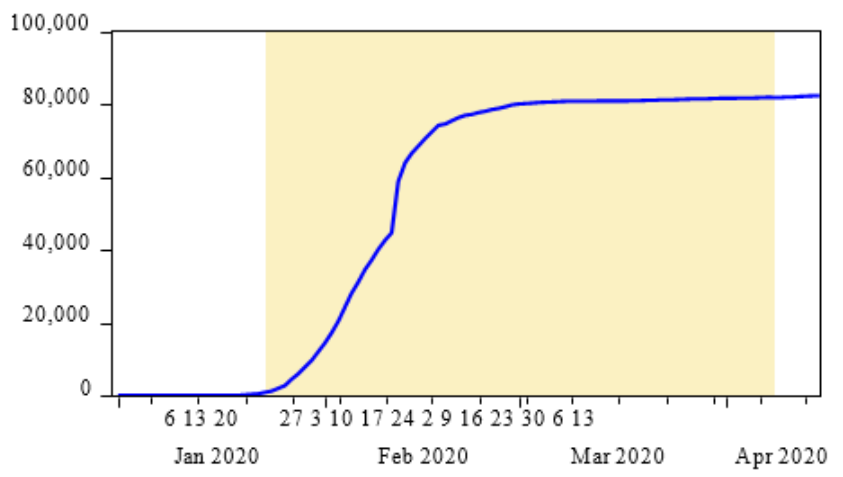

Daily new confirmed cases

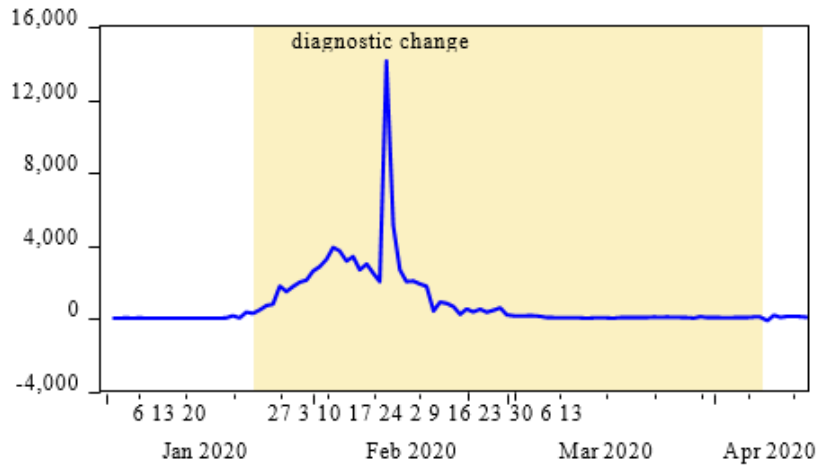

Total deaths

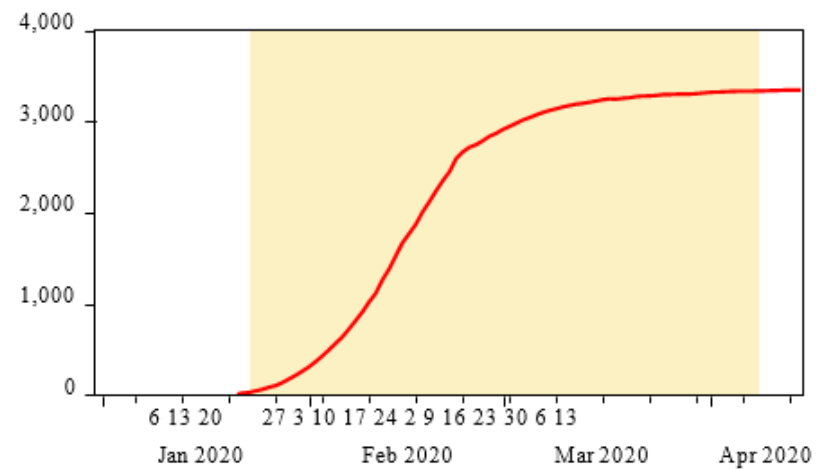

Daily deaths

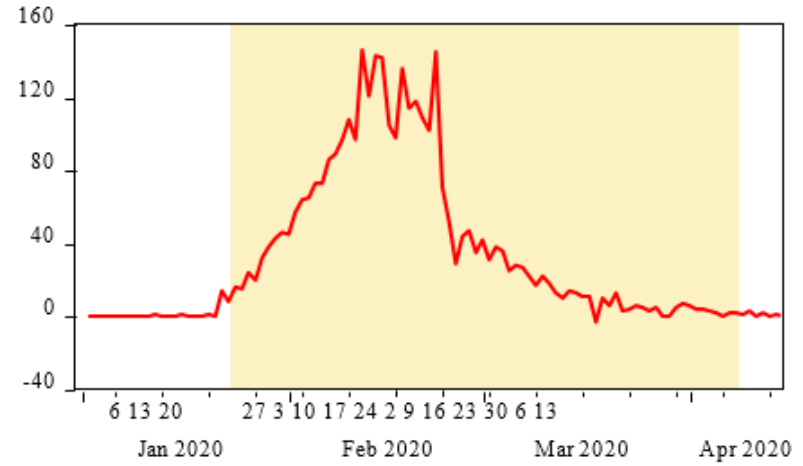

Source: Worldometer (2020).

Note: Shaded region denotes Wuhan lockdown period (23 January 2020 to 8 April 2020).

Figure 1

COVID-19 confirmed cases and deaths (31 December 2019 to 15 April 2020) 

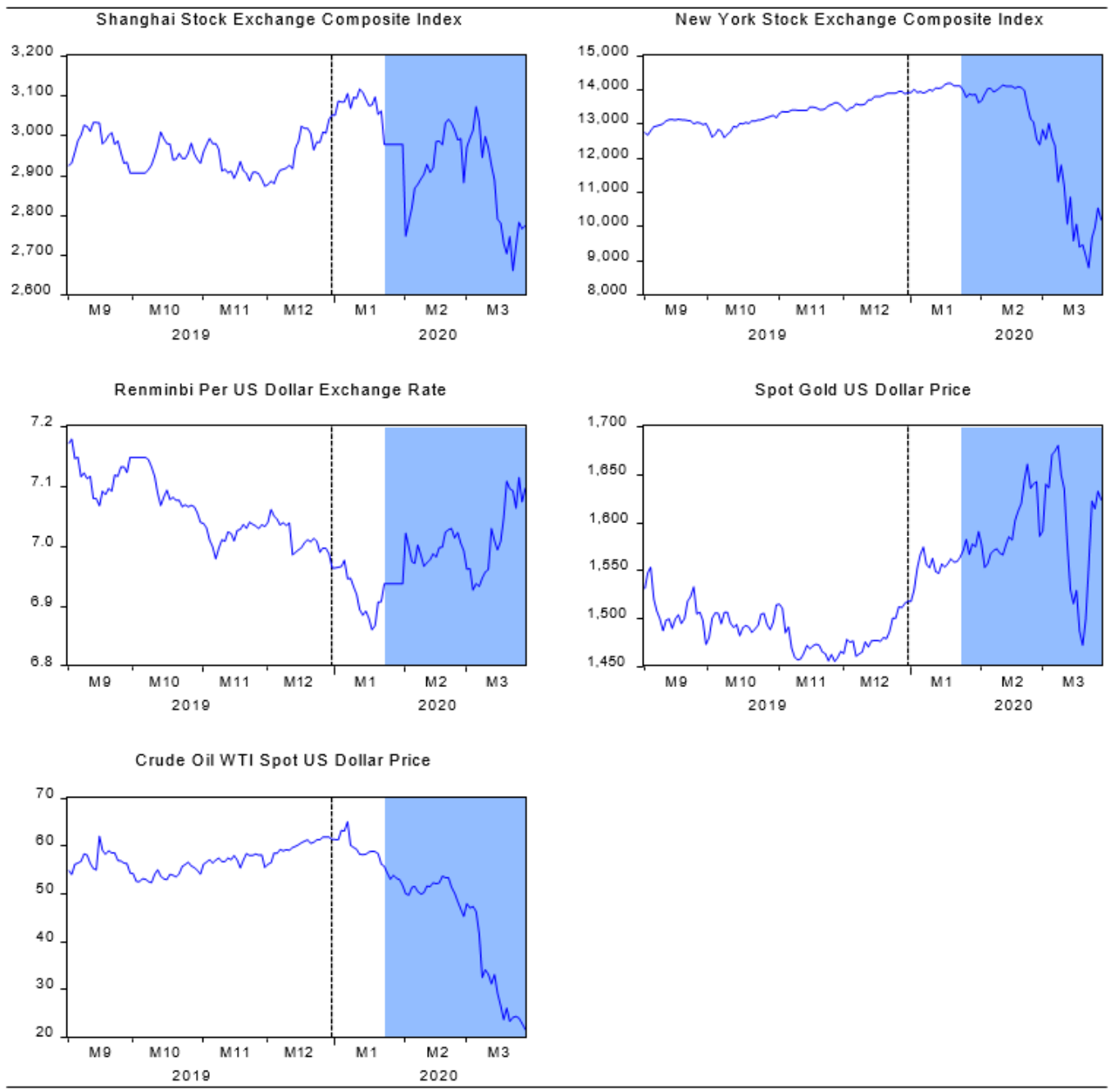

Notes: Dotted vertical line denotes 31 December 2019 when WHO first received COVID-19 official report. Shaded region denotes Wuhan lockdown period.

\section{Figure 2}

Time series plots of financial and commodities variables 

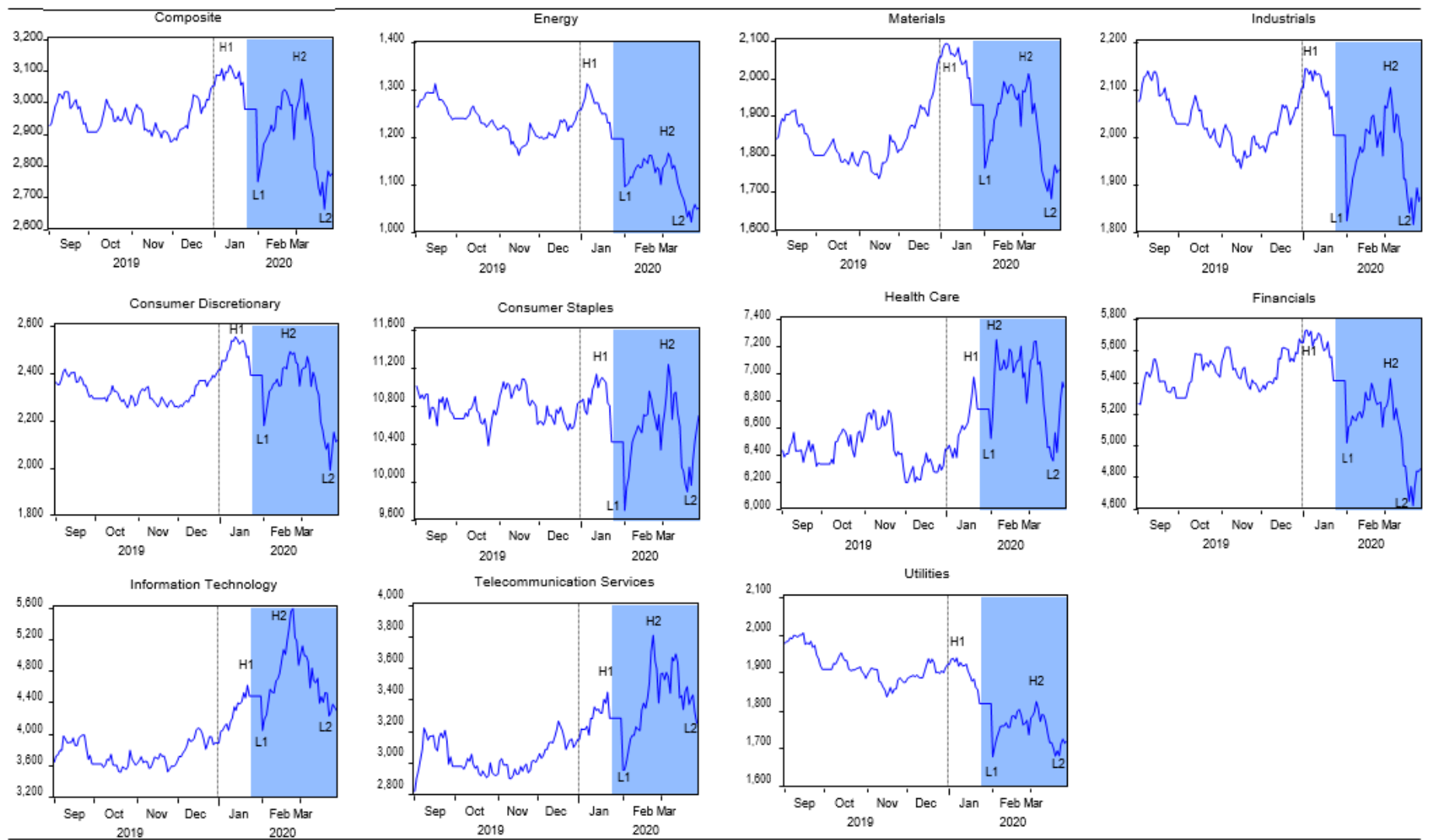

Note: Shaded region indicates Wuhan lockdown period (23 January 2020 to 27 March 2020). Dotted vertical line denotes 31 December 2019 when WHO first received COVID-19 official report. H1 denotes the index's peak (high) pre-Wuhan lockdown, while H2 refers to the next peak occurred on 5 March 2020 for majority of the indices. Conversely, L1 refers to the index's first bottom (low) (occurred on 3 February 2020), whereas L2 denotes the second bottom occurred on 23 March 2020 in most cases. Technically, if an index exhibits H2 $>\mathrm{H} 1$, one can say that it has a higher high. Similarly, H2 $<\mathrm{H} 1 \mathrm{means}$ lower high, L2 $<\mathrm{L} 1 \mathrm{means}$ lower low, and L2 > L1 means higher low.

\section{Figure 3}

Time series plots of Shanghai Stock Exchange composite and sectorial indices 